\title{
sciendo
}

\section{THE INFLUENCE OF RISK FACTORS ON THE CHOICE OF THERAPEUTIC METHOD IN PERIPHERAL ARTERIAL DISEASE}

\author{
OANA STOIA ${ }^{1}$, IOAN MANIȚIU ${ }^{2}$, IOAN BITEA ${ }^{3}$, GABRIELA EMINOVICI ${ }^{4}$, MINODORA \\ TEODORU $^{5}$ \\ ${ }^{1,3,4,5}$ Emergency County Clinical Hospital, Sibiu, ${ }^{1,2,4,5}$ "Lucian Blaga” University of Sibiu, Invasive and Non-invasive Research Center in the Field of \\ Cardiac and Vascular Pathology in Adults, Sibiu
}

\begin{abstract}
Keywords: peripheral, arterial, disease, drug, therapy, risk factors

Abstract: Peripheral arterial disease (PAD) is characterized by obstruction in the lower limbs, mainly due to atherosclerosis. The prevalence of the pathology in people under 40 years of age is $6 \%$ and $15-20 \%$ in the population over 65 years old. $(1,2)$ Approximately $50 \%$ of the affected persons are, at the time of examination, asymptomatic.(3) The most important risk factors associated with this condition are smoking, diabetes mellitus (DM), high cholesterol and high blood pressure (HBP). The current study shows that, regardless of the association of risk factors or pre-hospital treatment, these patients do not benefit from a certain type of treatment (drug or interventional), which corresponds to the existing data in the literature, which do not document the choice of type of treatment depending on the patient's age or comorbidities.
\end{abstract}

\begin{abstract}
INTRODUCTION
Peripheral arterial disease of the lower limbs is a pathology that refers to acute or chronic obstruction of the arteries in the lower limbs. There are several causes of this obstruction, for example, embolism, thrombosis, vasculitis, diseases that generally affect the arteries, although the most common is the atherosclerotic one.(4)

Atherosclerotic damage to the arteries of the lower limbs is correlated with an increased risk of developing major cardiovascular events, by deposition of atheroma plaques in the coronary and cerebral arteries.(5)

These patients may present with various pathologies, so the damage to the arteries by atherosclerosis should be sought in more detail, even if there are no obvious symptoms. Peripheral arterial disease is a major economic health problem, and it is estimated that over 200 million people worldwide are affected by this disease, of which at least $20 \%$ have some degree of claudication.(6) The investigation of the patient is a detailed one, with his history, screening for comorbidities, risk factors and even the presence of disabilities.

The anamnesis also includes the associated symptoms, such as dyspnea and NYHA class, the classification of angina pectoris according to the Canadian classification, the appearance of intermittent claudication for patients with peripheral arterial disease. Along with the consumption of toxins, the patient's adherence to the current medication must be evaluated.
\end{abstract}

\section{AIM}

The present paper aims to make correlations between classical drug therapy and interventional therapy for peripheral arterial disease, in association with various risk factors.

\section{MATERIALS AND METHODS}

For the current research, 51 patients were evaluated for the diagnosis of peripheral arterial disease of the lower limbs, evaluated by invasive methods during 2017-2018, in the Cardiology Clinic of the Sibiu County Emergency Clinical Hospital and in the Invasive and Noninvasive Research Center in the Field of Cardiac and Vascular Pathology in adults.

For all these patients selected for inclusion in the current study the following were performed:

- Agreement for the inclusion in the database of the hospital, without the appearance of personal data.

- Ankle - brachial index - which had values lower than 0.9 (the patient presents asymptomatic or symptomatic pathology with trophic lesions); $(7,8)$, with the patient's classification in the Leriche - Fontaine classification for arteriopathy.

- Arterial ultrasound of the lower limbs, which shows atherosclerotic lesions, with different degrees of damage. Ultrasound was performed by experienced cardiologists, although there were interobserver differences.

The following types of patients were excluded from the study:

1. patients with painful complaints in the lower limbs, but in whom the arm ankle index had values higher than 0.9.

2. patients who have received surgical treatment by amputation of the affected lower limb.

3. patients who were in stage IV Leriche-Fontaine.

For the statistical processing of the data from the current study, the Microsoft Excel programs from Microsoft Office Professional Account 2016 and SPSS 20 were used.

\section{RESULTS}

The study group included 51 patients aged between 46 and 83 years, with a predominance of males with a number of 39 patients.

There is also a predominance between $60-69$ years, with a number of 20 patients, which represents $39.22 \%$ (figure no. 1).

${ }^{1}$ Corresponding author: Oana Stoia, Str. Nottara, Nr. 6/38, Sibiu, România, E-mail: motoc.oana@yahoo.com, Phone: +40745 974335 Article received on 04.10 .2020 and accepted for publication on 02.12 .2020 


\section{CLINICAL ASPECTS}

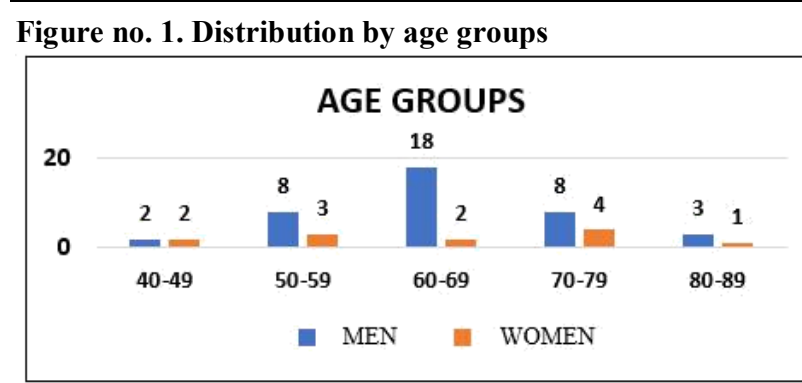

Figure no. 2. Distribution of risk factors for females

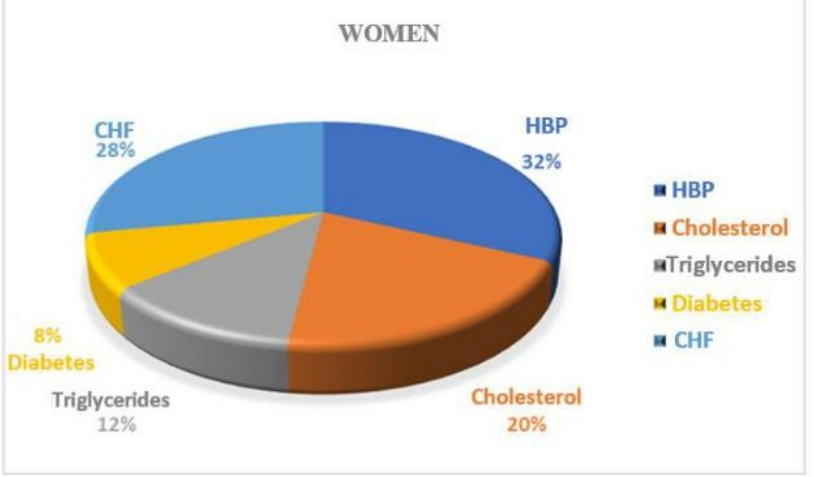

Figure no. 3. Distribution of risk factors for males

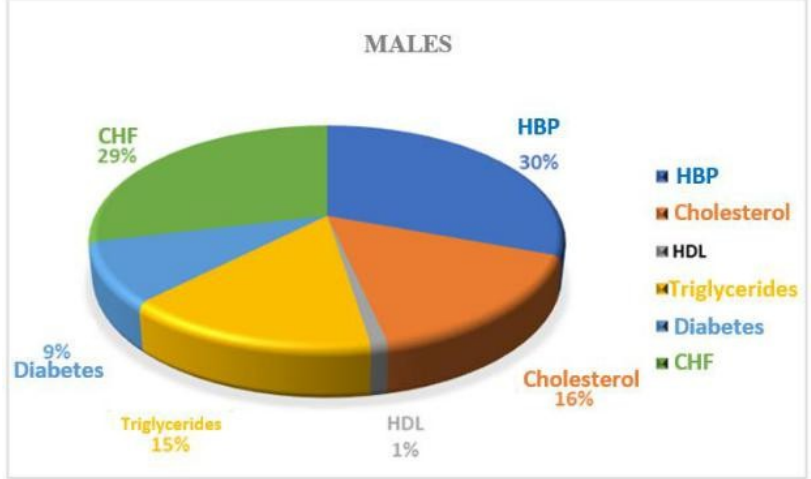

The association of approximately one third of these selected patients with ischemic heart disease and / or clinically and para-clinically diagnosed heart failure is observed (figure no. 2, figure no. 3). The mechanism by which inflammation along with diabetes and smoking occurs in the occurrence of heart failure in patients with PAD is well known.(9) Atherosclerosis, being the most common cause of peripheral arterial disease, also causes involvement in the coronary arteries, ischemic heart disease and heart failure.(10) There may also be patients underdiagnosed due to heart failure, who limit their movements and especially walking, due to cardiac symptoms and thus masking claudication.

Also, in the studied group it is observed that hypertension and ischemic heart disease are the most important risk factors for this pathology. The status of smoker does not have a big involvement in this group either, because only $37.25 \%$ are smokers, which does not correspond to the data in the literature.(11)

The treatment of this pathology involves several classes of drugs, especially since these patients are not only with peripheral arterial pathology, but they also associate diabetes, hypertension or dyslipidemia. In general, these patients benefit from statins, antiplatelet agents, but also vasodilators, such as cilostazol. Alprostadil is another drug used to treat these patients, although it is not present in the guidelines of the
European Society of Cardiology.(8)

If we evaluate patients who received interventional treatment, compared to those who have chronic treatment with cilostazol, there is a weak but statistically significant difference between the percentage of patients treated with cilostazol who subsequently needed intervention and those whose clinical condition improved remaining on drug treatment $(23.5 \%$ vs. $56 \%$, df1, $\mathrm{p}=0.029$ ) (table no.1, table no. 2).

Table no. 1. The relationship of patients who received drug treatment vs. intervention treatment. Cilostazol * interventional treatment Crosstabulation

\begin{tabular}{|cc|c|c|c|}
\hline & & \multicolumn{2}{|c|}{ Interv } & \multirow{2}{*}{ Total } \\
\cline { 3 - 4 } & & 0 & 1 & \\
\hline cilostazol & 0 Count & 15 & 19 & 34 \\
& \% within cilostazol & & & \\
& & $44.1 \%$ & $55.9 \%$ & $100.0 \%$ \\
& \% within interv. & $53.6 \%$ & $82.6 \%$ & $66.7 \%$ \\
\cline { 2 - 4 } & 1 Count & 13 & 4 & 17 \\
& \% within cilostazol & $76.5 \%$ & $23.5 \%$ & $100.0 \%$ \\
& \% within interv. & $46.4 \%$ & $17.4 \%$ & $33.3 \%$ \\
\hline Total & Count & 28 & 23 & 51 \\
& \% within cilostazol & $54.9 \%$ & $45.1 \%$ & $100.0 \%$ \\
& \% within interv. & $100.0 \%$ & $100.0 \%$ & $100.0 \%$ \\
\hline
\end{tabular}

Table no. 2. Correlation between Alprostadil administration and the need for interventional treatment. Alprostadil * interventional treatment Crosstabulation

\begin{tabular}{|ll|c|c|c|}
\hline & & \multicolumn{2}{|c|}{ Interv. } & \multirow{2}{*}{ Total } \\
\cline { 3 - 4 } & & 0 & 1 & \\
\hline Alprostadil & 0 Count & 22 & 18 & 40 \\
& \% within Alprostadil & $55.0 \%$ & $45.0 \%$ & $100.0 \%$ \\
& \% within interv & $78.6 \%$ & $78.3 \%$ & $78.4 \%$ \\
\cline { 2 - 4 } & 1 Count & 6 & 5 & 11 \\
& \% within Alprostadil & $54.5 \%$ & $45.5 \%$ & $100.0 \%$ \\
& \% within interv. & $21.4 \%$ & $21.7 \%$ & $21.6 \%$ \\
\hline Total & Count & 28 & 23 & 51 \\
& \% within Alprostadil & $54.9 \%$ & $45.1 \%$ & $100.0 \%$ \\
& \% within interv. & $100.0 \%$ & $100.0 \%$ & $100.0 \%$ \\
\hline
\end{tabular}

If a comparison is made between treatment with infusion solutions with alprostadil (Vasaprostan) and interventional treatment, a weak and statistically insignificant difference is observed $(\mathrm{p}=0.979)$.

Observing that there are no statistically significant values for vasodilator treatment compared to the interventional one, it was decided to evaluate whether the risk factors have an impact on the chosen type of treatment.

Table no. 3. Correlation analysis

Descriptive Statistics

\begin{tabular}{|l|c|c|c|}
\hline & Mean & Std. Deviation & $\mathrm{N}$ \\
\hline Age & 65.19 & 9.958 & 53 \\
BMI & 26.688 & 4.0768 & 53 \\
\hline
\end{tabular}

Correlations

\begin{tabular}{|ll|c|c|}
\hline & & Age & BMI \\
\hline Pearson Correlation & age & 1.000 & -.034 \\
& BMI & -.034 & 1.000 \\
\hline Sig. (1-tailed) & age &. & .403 \\
& BMI & .403 &. \\
\hline $\mathrm{N}$ & Age & 53 & 53 \\
& BMI & 53 & 53 \\
\hline
\end{tabular}

From the tables above, we conclude that the correlation analysis did not identify any relationship between the two predictive factors (BMI and age) (table no. 3).

Thus, we show that in the regression equation body mass index (BMI) has a negative influence (higher BMI will determine a choice of drug therapy), but without having a statistical significance (an increase by one unit of BMI will 


\section{CLINICAL ASPECTS}

cause a decrease of 0.246 times the chance of interventional treatment), with $\mathrm{T}=-0.246$ and $\mathrm{p}=0.806$ (table no. 4 ).

Table no. 4. BMI regression equation

ANOVA $^{\text {a }}$ Model
\begin{tabular}{|l|l|l|l|l|c|}
\hline \multicolumn{1}{|c|}{$\begin{array}{c}\text { Sum of } \\
\text { Squares }\end{array}$} & \multicolumn{1}{c|}{ df } & $\begin{array}{c}\text { Mean } \\
\text { Square }\end{array}$ & F & Sig. \\
\hline 1 Regression & 6.127 & 1 & 6.127 & .061 & $.806^{\mathrm{b}}$ \\
\hline Residual & 5149.986 & 51 & 100.980 & & \\
\hline Total & 5156.113 & 52 & & & \\
\hline
\end{tabular}

a. Dependent Variable: age

b. Predictors: (Constant), BMI

\section{Coefficients}

\begin{tabular}{|c|c|c|c|c|c|}
\hline \multirow{3}{*}{ Model } & \multicolumn{2}{|c|}{$\begin{array}{c}\text { Unstandardized } \\
\text { Coefficients }\end{array}$} & $\begin{array}{c}\text { Standardized } \\
\text { Coefficients }\end{array}$ & \multirow{2}{*}{ T } & \multirow{2}{*}{ Sig. } \\
\cline { 2 - 4 } & B & $\begin{array}{c}\text { Std. } \\
\text { Error }\end{array}$ & Beta & & \\
\hline 1 (Constant) & 67.436 & 9.226 & & 7.309 & .000 \\
\hline BMI & -.084 & .342 & -.034 & -.246 & .806 \\
\hline
\end{tabular}

a. Dependent Variable: age

Table no. 5. Age relationship - BMI

Variables in the Equation

\begin{tabular}{|c|c|c|c|c|c|c|c|c|}
\hline \multirow[t]{2}{*}{ Step } & \multirow[t]{2}{*}{ B } & \multirow[t]{2}{*}{ S.E } & \multirow[t]{2}{*}{ Wald } & \multirow[t]{2}{*}{ df } & \multirow[t]{2}{*}{ Sig. } & \multirow[t]{2}{*}{$\operatorname{Exp}(B)$} & \multicolumn{2}{|c|}{$\begin{array}{l}\text { 95\% C.I for EXP } \\
\text { (B) }\end{array}$} \\
\hline & & & & & & & Lower & Upper \\
\hline $1^{\mathrm{a}}$ age & .029 & .029 & .980 & 1 & .322 & 1.029 & .972 & 1.089 \\
\hline BMI & $\begin{array}{l}-.025 \\
\end{array}$ & .070 & .127 & 1 & .721 & .975 & .851 & 1.118 \\
\hline Constant & -1.399 & 2.690 & .270 & 1 & .603 & .247 & & \\
\hline
\end{tabular}

a. Variable(s) entered on step 1: age, BMI.

Thus, we can demonstrate that the two variables, age and BMI, increase predictability to $58.8 \%$. We also note that age is a positive indicator, so an increase of 0.029 in age will lead to an increase in the chance of interventional treatment of 1.029 , but due to the low number of cases it is not a statistical significance ( $p=0.322$, CI: 0.972 to 1.089$)$ (table no. 5).

Regarding the BMI we notice that a decrease of 0.025 of the BMI, will lead to an increase of the chance of interventional treatment of 0.975 , also without statistical significance $(p=0.721$, CI: $0.8-1.1)$.

\section{DISCUSSIONS}

PAD is underdiagnosed because these patients present with various symptoms, from pain to walking, but also at rest that can be confused with pain due to degenerative changes in the joints, the patients being advanced in age.(3) The current study included stable patients, known to have intermittent claudication that occurred both while walking and at rest, who presented to the cardiology department on a scheduled basis for thorough investigations of peripheral arterial pathology. It included a number of 51 patients from all social backgrounds.

It was observed that the maximum incidence of peripheral vascular pathology is $50-79$ years, meaning $84.32 \%$, although a comparative study between males and females cannot be performed, due to the low number of patients. These data correspond to the data in the literature, which states that the incidence of peripheral arterial disease is more common in the second and third age, meaning it increases with age and the appearance of atheroma plaques. $(1,2)$

The predisposing risk factors for the occurrence of peripheral arterial disease of the lower limbs are smoking, which is also possibly modifiable, HBP, DM and hypercholesterolemia. If the drug treatment included in the ESC guidelines for the treatment of PAD (8), such as cilostazol or statins, was observed, was highlighted that there was no statistical correlation for patients treated with statins. Patients who received drug treatment with cilostazol, received a lower number of interventional treatment, and this being of statistical significance, with $p=0.029$, which coincides with the data in the medical literature, which places this drug in the first class of recommendation in the ESC guide.(8)

To see if there is a correlation between risk factors (smoking, HBP, DM, high cholesterol), the patient's background, sex or obesity and the need for interventional or drug treatment, several methods were used. statistical evaluation, but no significant differences were observed, nor were they statistically correlated by evaluating the value of $p$.

The existing data in the literature do not document the choice of treatment depending on the patient's age. The need for drug or interventional therapy in these patients was assessed by two known parameters, age and BMI, which were shown to increase predictability by more than $50 \%(58.8 \%)$, age being a positive indicator for interventional treatment, while an increased BMI opts for drug treatment (no statistical significance due to the small number of cases).

\section{CONCLUSIONS}

- Peripheral arterial disease is more common in elderly patients, with an average age of 65.09 years.

- Cilostazol reduced the need for interventional therapy, with statistical significance, by $\mathrm{p}=0.029$.

- The administration of statins did not influence the need for interventional therapy.

- No statistical correlation was observed between the origin of the patient, the risk factors or the sex of the patient and the therapeutic behavior (medicinal or interventional).

\section{REFERENCES}

1. Fowker FG, Rudan D, Rudan I, et al. Comparison of global estimates of prevalence and risk factors for peripheral artery disease in 2010 and 2010: a systemic review and analysis. Lancet. 2013;382:1329-1340.

2. Criqui MH, Aboyans V. Epidemiology of peripheral artery disease. Circ Res. 2015;116:1509-1526.

3. Jacoby DS, Mohler ER. Peripheral arterial disease. Risk factor identification and modification. In: Abela GS, editor. Peripheral Vascular Disease. Basic Diagnostic and Therapeutic Approaches. Lippincott Williams and Wilkins; 2004. p. 190-9.

4. Zipes D, Libby P. Braunwald's Heart Disease: A Textbook of Cardiovascular Medicine, 11th Edition; 2018.

5. Herman G, Gornik HL, Barrett C, et al.2016 AHA/ACC guideline on the management of patients with lower extremity peripheral artery disease: a report of the American College of Cardiology/ American Heart Association Task Force on Clinical Practice Guidelines. Circulation. 2017;135:e726-e779.

6. Tseng A, Louka B, Shamoun F, Esser H, Morcos R, McBane, Misra RS. The Evolving Treatment of Peripheral Arterial Disease through Guideline - Directed Recommandations, J Clin Med. 2018 Jan; 2018;7(1):9.

7. Costel M. Bolile arterelor periferice. In Ginghină C et al. Mic tratat de cardiologie. București. Editura Academiei Române; 2017; p. 967-77.

8. Aboyans V, Ricco JB, et al. 2017 ESC Guidelines on the Diagnosis and Treatment of Peripheral Arterial Diseases, in collaboration with the European Society for Vascular Surgery (ESVS): Document covering atherosclerotic disease of extracranial carotid and vertebral, mesenteric, renal, upper and lower extremity arteries. European Heart Journal. 2018;39(9):763- 816.

9. Rauchhaus M, Doehner W, Francis DP, Davos C, Kemp M, Lie- benthal C, Niebauer J, Hooper J, Volk HD, Coats AJ, Anker SD. Plasma cytokine parameters and mortality in 
CLINICAL ASPECTS

patients with chronic heart failure. Circulation 2000;102:3060-3067.

10. Ostergren J, Sleight P, Dagenais G, Danisa K, Bosch J, Qilong Y, Yusuf S. Impact of ramipril in patients with evidence of clinical or subclinical peripheral arterial disease. Eur Heart J. 2004;25:17-24.

11. Joosten MM, Pai JK, Bertoia ML, Rimm EB, Spiegelman D, Mittleman MA, Mukamal KJ. Associations between conventional cardiovascular risk factors and risk of peripheral artery disease in men. JAMA.2012;308:16601667. doi:10.1001/jama.2012.13415. 